\title{
O processo de insolvência e o tratamento das microempresas e empresas de pequeno porte em crise no Brasil
}

\author{
The treatment of small and medium-sized enterprises insolvency in Brazil
}

\author{
Marcelo Barbosa Sacramone* \\ Ivo Waisberg ** \\ Marcelo Guedes Nunes ${ }^{* * *}$ \\ Renato Scardoa ${ }^{* * * *}$
}

\section{Resumo}

O presente artigo analisa se o instituto da recuperação judicial, tal como disciplinado pela legislação nacional, é mecanismo eficiente de superação da crise econômico-financeira que pode acometer as atividades dos microempresários e empresários de pequeno porte no Brasil. A abordagem jurimétrica de todos os processos de recuperação judicial distribuídos no estado de São Paulo, entre 2010 e 2018, é realizada sob uma perspectiva descritiva. Por meio da mensuração das diversas variáveis durante as etapas do procedimento de recuperação judicial, identifica-se se o instituto é uma alternativa viável aos pequenos empresários e quais suas principais dificuldades. A análise permite verificar que os custos e a exigência de apresentação de documentação contábil revelam-se como barreiras de entrada aos pequenos empresários. Por seu turno, diante da média dos planos de recuperação judicial aprovados e da quantidade de recuperandas que optaram pelo procedimento especial, a redução das despesas pretendida pelo procedimento especial não é relevante a ponto de compensar as diversas limitações impostas ao plano de recuperação a ser proposto.

Palavraschave: Insolvência. Microempresa. Empresa de pequeno porte. Recuperação judicial.

\section{Abstract}

This article analyzes the judicial reorganization institute, as regulated by Brazilian national legislation, it is an efficient mechanism for small and medium-sized enterprises (SME) to overcome the economic and financial crisis. The jurimetrics of all SME reorganization cases filed in Sao Paulo on or after 2010 to 2018 are held under a descriptive perspective. For the measurement of several variables during the stages of the reorganization procedure, the enables routine to identify if the institute is a viable alternative for SMEs and what are their main difficulties. This analysis allows to verify if the costs and the presentation of the accounting record are barriers for SMEs to entry into judicial reorganization. In turn, given the average of judicial reorganization plans and the number of SMEs that opted for their special procedure, a reduction in cost predetermined by the special procedure is not relevant to a point of compensation, as are several restrictions imposed on the recovery plan a be executed.

Keywords: Insolvency. Small and medium-sized enterprises. Reorganization.

Doutor e Mestre em Direito Comercial pela Universidade de São Paulo. Professor da Pontifícia Universidade Católica de São Paulo e da Escola Paulista da Magistratura. Juiz de Direito em exercício na $2^{a}$ Vara de Falência e Recuperação Judicial do Foro Central da Comarca de São Paulo. São Paulo - SP - Brasil. E-mail: marcelosacramone@yahoo.com.br.

Professor da Pontifícia Universidade Católica de São Paulo. Livre docente em Direito Comercial. Doutor em Direito das Relações Econômicas Internacionais e mestre em Direito Comercial pela Pontifícia Universidade Católica de São Paulo. LLM in trade regulation pela NYU. Advogado em São Paulo. São Paulo - SP - Brasil. E-mail: ivo@twk.com.br.

*** Professor da Pontifícia Universidade Católica de São Paulo. Doutor e mestre em Direito Comercial pela Pontifícia Universidade Católica de São Paulo. Advogado em São Paulo. Presidente da Associação Brasileira de Jurimetria. São Paulo - SP - Brasil. E-mail: mnunes@gnor.com.br.

*** Doutorando em Direito Comercial pela Faculdade de Direito da Universidade de São Paulo. Mestre em Direito das Relações Internacionais e graduado em Direito pela Pontifícia Universidade Católica de São Paulo. Advogado em São Paulo. São Paulo - SP - Brasil. E-mail: rscardoa@ gvmail.br. 


\section{Introdução}

O conceito de eficiência pode ser definido de diversas formas pelos economistas. Para Pareto, eficiente é a situação em que o resultado obtido não pode ser alterado sem que qualquer pessoa envolvida fique em situação pior do que a inicial. Para Kaldor-Hicks, eficiente é a situação em que ao menos o ganho gerado por uma das partes possa compensar as perdas dos demais envolvidos (POSNER, 2011, p. 19).

A eficiência da alocação de recursos diante da insolvabilidade do empresário é pretendida pelas diversas leis de insolvência. ${ }^{1}$ Sua criação decorreria da inadequação do sistema de execuções individuais para satisfazer a coletividade dos credores do empresário insolvável (BAIRD; JACKSON, 1984, p. 101103) e para assegurar a proteção dos interesses de todos os demais envolvidos com o desenvolvimento da atividade empresarial (KOROBKIN, 1992, p. 335).

Ainda que possa haver alguma controvérsia sobre os objetivos pretendidos, ${ }^{2}$ podem ser destacados como principais objetivos de um sistema de insolvência: a busca pela maximização de valor dos ativos e a redução dos custos para a satisfação de toda a coletividade dos credores (JACKSON, 1986, p. 15); a apropriada alocação dos custos do insucesso ao devedor, para que não tenha estímulo a se tornar inadimplente; e a distribuição apropriada dos valores entre os interessados. ${ }^{3}$

No sistema de insolvência, tais objetivos são aplicáveis tanto aos procedimentos falimentares quanto recuperacionais. Em linhas gerais, na falência, diante da inviabilidade econômica da manutenção da atividade sob a condução do empresário devedor, os credores, individualmente, não poderiam provocar o fracionamento dos estabelecimentos empresariais em detrimento da maximização do valor dos ativos e da maior satisfação de todos os interessados.

$\mathrm{Na}$ falência, para tanto, criam-se regras para incentivar os comportamentos coletivos e reduzir as estratégias individuais com o intuito de preservar e otimizar a utilização produtiva dos bens na liquidação forçada. A alienação dos ativos, sem a fragmentação pretendida, permitiria a obtenção de maiores valores para a satisfação de todos os créditos, sem prejuízo de também satisfazer os interesses de todos os demais envolvidos com a manutenção do desenvolvimento da atividade, agora sob a condução do empresário arrematante (PUGLIESI, 2013).

Também são aplicáveis esses objetivos ao procedimento de recuperação judicial. Diante de uma crise econômica temporária, poderá ser mais conveniente aos credores e demais interessados na atividade conservar o desenvolvimento da atividade empresarial sob a condução do próprio devedor. Embora o protelamento da decretação de uma liquidação forçada de uma empresa economicamente inviável possa gerar maior consumo de recursos escassos pelo devedor inadimplente, em benefício próprio, e resultar em maiores perdas aos interessados, a preservação da empresa economicamente viável sob a condução do devedor poderia assegurar a manutenção das relações jurídicas estabelecidas e maiores condições para a satisfação de todos credores e demais interessados.

Dessa forma, por meio do procedimento da recuperação judicial, cria a Lei n. ${ }^{0} 11.101 / 2005$ (Lei de Insolvência) ambiente institucional de estímulo a comportamentos coletivos, por meio da suspensão de ações e execuções e do estabelecimento de quóruns de deliberação por maioria. Tais regras permitiriam aos credores avaliarem a viabilidade econômica da preservação da atividade sob a condução do devedor e

Conforme relatório do senador Ramez Tebet apresentado à Comissão de Assuntos Econômicos em relação ao PLC 71/2003, "nosso trabalho pautou-se não apenas pelo objetivo de aumento da eficiência econômica - que a lei sempre deve propiciar e incentivar - mas, principalmente, pela missão de dar conteúdo social à legislação" (TEBET, 2007).

Para Warren (1993, p. 343-344), quatro são os objetivos: "(1) to enhance the value of the failing debtor; (2) to distribute value according to multiple normative principles; (3) to internalize the costs of the business failure to the parties dealing with the debtor; and (4) to create reliance on private monitoring".

Em seu relatório ao PLC 71/2003, o senador Ramez Tebet apresenta 12 princípios adotados no projeto e nas modificações propostas: preservação da empresa; separação dos conceitos de empresa e de empresário; recuperação das sociedades e empresários recuperáveis; retirada do mercado de sociedades ou empresários não recuperáveis; proteção aos trabalhadores; redução do custo do crédito no Brasil; celeridade e eficiência dos processos judiciais; segurança jurídica; participação ativa dos credores; maximização do valor dos ativos do falido; desburocratização da recuperação de microempresas e empresas de pequeno porte; rigor na punição de crimes relacionados à falência e à recuperação judicial (TEBET, 2007). 
se os meios por ele propostos no plano de recuperação seriam suficientes para superar a crise econômica de sua atividade, com maior satisfação de seus interesses em comparação a uma liquidação falimentar.

A eficiência da alocação de recursos pretendida pela legislação de insolvência, conforme esses objetivos, pode ser decomposta em ex post e ex ante.

Na eficiência ex post, após a insolvabilidade do devedor e independentemente do procedimento a ser adotado, recuperacional ou falimentar, procura-se assegurar o maior valor dos ativos para a satisfação dos interessados (HART, 2000, p. 3).

Essa maximização do valor dos ativos conduz à eficiência ex ante. Com menores custos de controle em relação ao inadimplemento e maior satisfação coletiva dos créditos, reduzemse os custos de transação dos agentes econômicos. Nesses termos, "quanto maiores as garantias dadas aos credores antes da insolvência ou da iliquidez, menores os custos de transação relacionados ao curso das atividades da empresa" (SADDI; PINHEIRO, 2005, p. 209).

Diante desses objetivos pretendidos e antes de se iniciar a análise estatística dos casos de recuperação judicial do estado de São Paulo para se aferir sua eficiência, é importante ressaltar que "nenhuma lei recuperacional, por mais técnica que seja, pode substituir as soluções de mercado” (COELHO, 2010, p. 7). Outrossim, a avaliação da eficiência de uma determinada lei não pode ser feita de forma isolada. A satisfação dos objetivos pretendidos é dependente de diversas outras variáveis, além da estruturação formal de um procedimento adequado a ser aplicado, as quais poderiam alterar o resultado obtido, como: a especialização das varas judiciais, o treinamento dos juízes, o fortalecimento de controles societários etc. (HART, 2000, p. 1).

\section{O enquadramento dos empresários no estado de São Paulo e a distribuição das recuperandas por faturamento}

A eficiência de um sistema de insolvência geralmente é percebida conforme uma visão estreita de casos particulares, sem que se realize que processos emblemáticos podem não ser representativos do todo. Há, portanto, vieses (de disponibilidade, de confirmação, de sobrevivência, entre outros) capazes de afetar a avaliação sobre os resultados objetivos do instituto da recuperação judicial. Tal percepção pode ser ainda mais enviesada diante da presença assimétrica das recuperandas por faturamento em relação aos empresários ativos existentes no estado de São Paulo.

Com a utilização da mesma população de casos da segunda fase do Observatório de Insolvência, ${ }^{4}$ foram analisados todos os processos de recuperação judicial distribuídos entre janeiro de 2010 e julho de 2017 no estado de São Paulo (WAISBERG et al., 2019), partindo-se dos mesmos recortes temporal e espacial, que serão aqui utilizados para a aferição das demais variáveis envolvidas neste estudo.

A coleta, posteriormente revisada, resultou em 851 processos de recuperações judiciais distribuídos nas comarcas do estado de São Paulo ${ }^{5}$, cujos faturamentos das requerentes, baseados na receita operacional bruta do último exercício fiscal anterior à distribuição, foram analisados.

\footnotetext{
Pesquisa coordenada por Ivo Waisberg, Marcelo Sacramone, Marcelo Guedes Nunes e Fernando Corrêa, e publicada em 2019.

De um total de 906 processos de recuperação judicial analisados pela $2^{\mathrm{a}}$ Fase do Observatório da Insolvência, foram excluídos 56 processos em razão de conflito de competência e por serem incidentes e não processos principais, assim como foi incluído mais um processo de recuperação judicial.
} 
Figura 1: Distribuição das requerentes de acordo com a faixa de faturamento.

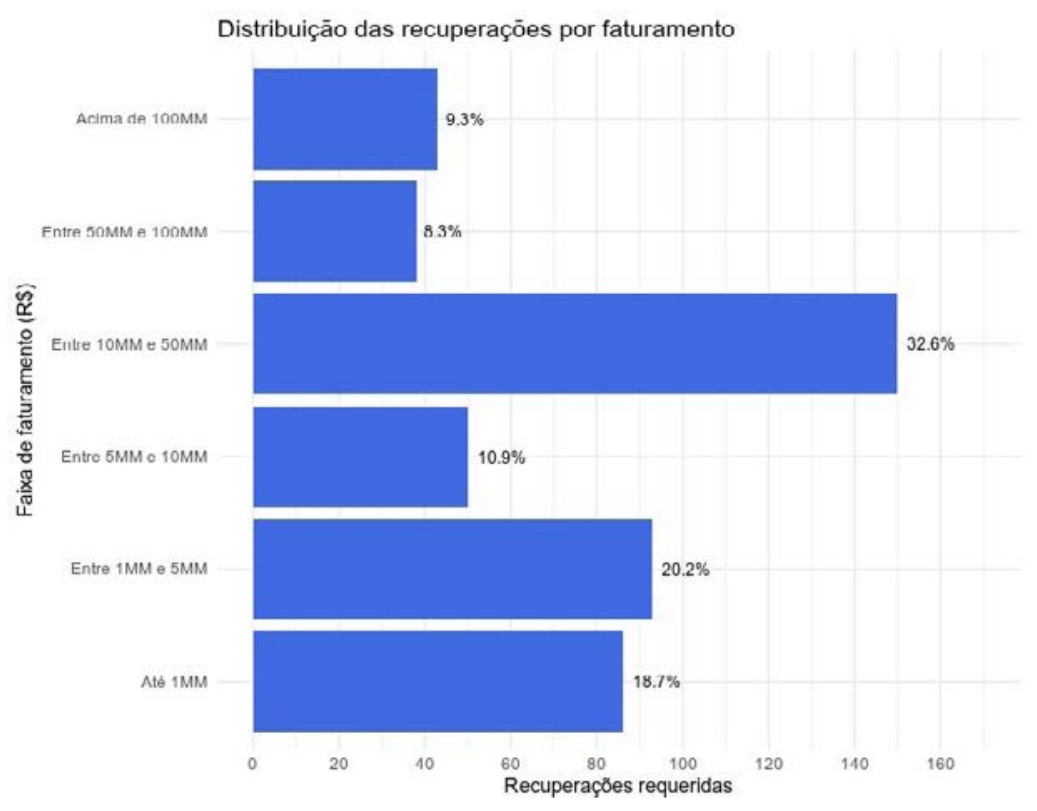

A partir do gráfico, verifica-se que $38,9 \%$ dos empresários em recuperação judicial apresentaram faturamento anual de até $R \$ 5.000 .000,00$. Nesse subconjunto estariam incluídos os microempresários e empresários de pequeno porte (MEs e EPPs), que preencheram os demais requisitos da Lei de Insolvência.

O conceito geral de MEs e EPPs é definido pela LC 123/06. Para seus fins e por ocasião da coleta dos processos distribuídos até 31 de julho de 2017, são consideradas MEs e EPPs a sociedade empresária, a sociedade simples, a empresa individual de responsabilidade limitada e o empresário que, para as MEs, tiveram faturamento de até $R \$ 360.000,00$, e, para os EPPs, tenham tido de $R \$ 360.000,00$ a $R \$$ $3.600 .000,00$, desde que não se incluam em determinadas hipóteses excludentes ${ }^{6}$. Esse último valor para as EPPs foi majorado para $R \$ 4.800 .000,00$ pela Lei Complementar $n .^{\circ} 155 / 2016$, mas somente passou a produzir efeitos a partir de $1^{\circ}$ de janeiro de 2018 , de modo que é irrelevante para a pesquisa.

Desse universo, contudo, para fins de submissão ao procedimento de recuperação judicial, os arts. $1^{\circ}$ e 70 da Lei de Insolvência exigiram a condição de o devedor caracterizarse como empresário. As sociedades simples, dessa forma, ainda que enquadradas como MEs e EPPs, não são consideradas para fins da Lei de Insolvência.

Da mesma forma, nota-se que o legislador optou por aplicar as exceções previstas pelo art. $3^{\circ}$, $\S 4^{\circ}$, da LC 123/06 apenas para fins daquela lei, ressaltando, inclusive, esse efeito para fins tributários em seu

\footnotetext{
LC $123 / 06$ - "Art. $3^{\circ}$ Para os efeitos desta Lei Complementar, consideram-se microempresas ou empresas de pequeno porte, a sociedade empresária, a sociedade simples, a empresa individual de responsabilidade limitada e o empresário a que se refere o art. 966 da Lei $n^{\circ} 10.406$, de 10 de janeiro de 2002 (Código Civil), devidamente registrados no Registro de Empresas Mercantis ou no Registro Civil de Pessoas Jurídicas, conforme o caso, desde que: I-no caso da microempresa, aufira, em cada ano-calendário, receita bruta igual ou inferior a R $\$ 360.000,00 ; \mathrm{e}$ II - no caso de empresa de pequeno porte, aufira, em cada ano-calendário, receita bruta superior a $\mathrm{R} \$ 360.000,00$ e igual ou inferior a $\mathrm{R} \$ 4.800 .000,00$. [...] $\S 4^{\circ}$ Não poderá se beneficiar do tratamento jurídico diferenciado previsto nesta Lei Complementar, incluído o regime de que trata o art. 12 desta Lei Complementar, para nenhum efeito legal, a pessoa jurídica: I - de cujo capital participe outra pessoa jurídica; II - que seja filial, sucursal, agência ou representação, no País, de pessoa jurídica com sede no exterior; III - de cujo capital participe pessoa física que seja inscrita como empresário ou seja sócia de outra empresa que receba tratamento jurídico diferenciado nos termos desta Lei Complementar, desde que a receita bruta global ultrapasse o limite de que trata o inciso II do caput deste artigo; IV - cujo titular ou sócio participe com mais de $10 \%$ (dez por cento) do capital de outra empresa não beneficiada por esta Lei Complementar, desde que a receita bruta global ultrapasse o limite de que trata o inciso II do caput deste artigo; $V$ - cujo sócio ou titular seja administrador ou equiparado de outra pessoa jurídica com fins lucrativos, desde que a receita bruta global ultrapasse o limite de que trata o inciso II do caput deste artigo; VI - constituída sob a forma de cooperativas, salvo as de consumo; VII - que participe do capital de outra pessoa jurídica; VIII - que exerça atividade de banco comercial, de investimentos e de desenvolvimento, de caixa econômica, de sociedade de crédito, financiamento e investimento ou de crédito imobiliário, de corretora ou de distribuidora de títulos, valores mobiliários e câmbio, de empresa de arrendamento mercantil, de seguros privados e de capitalização ou de previdência complementar; IX - resultante ou remanescente de cisão ou qualquer outra forma de desmembramento de pessoa jurídica que tenha ocorrido em um dos 5 (cinco) anos-calendário anteriores; $X$ - constituída sob a forma de sociedade por ações. XI - cujos titulares ou sócios guardem, cumulativamente, com o contratante do serviço, relação de pessoalidade, subordinação e habitualidade. [...]".
} 
$\S 6^{0} .^{7}$ Essas mesmas exceções não foram aplicadas para fins de recuperação judicial e falência, nem pela LC 123/06, nem pela Lei de Insolvência.

Pelos dados coletados, os devedores que possuem faturamento de até $\mathrm{R} \$ 5.000 .000,00$ e que, portanto, englobariam aqueles que se enquadrariam como MEs e EPPs até o faturamento de $R \$ 3.600 .000,00$, representariam, no máximo, $38,9 \%$ do total de empresários que se submeteram à recuperação judicial. Os dados, ao contrário de revelarem uma percepção de que a recuperação judicial seria uma alternativa disponibilizada a todos os empresários cuja atividade foi acometida por uma crise econômico-financeira, independentemente do faturamento, revela um viés de seleção da Lei de Insolvência.

De janeiro de 1980, início dos dados disponibilizados pela Junta Comercial do Estado de São Paulo, até 31 de julho de 2017, data final da coleta, estavam registrados no Registro Público de Empresas Mercantis paulista, como empresários ativos, 5.284.949 pessoas. Desse montante, 4.367.387 eram MEs, 281.726 eram EPPs e 635.836 eram outros empresários.

Tabela 1: Empresários registrados de acordo com o enquadramento.

\begin{tabular}{c|c|c}
\hline Tamanho da empresa & Frequência & $\%$ \\
\hline Microempresa (ME) & 4.367 .387 & $82,64 \%$ \\
\hline Pequeno porte (EPP) & 281.726 & $5,33 \%$ \\
\hline $\begin{array}{c}\text { Demais } \\
\text { empresários }\end{array}$ & 635.836 & $12,03 \%$ \\
\hline Total & 5.284 .949 & $100 \%$ \\
\hline
\end{tabular}

Além de consistirem em $87,97 \%$ dos empresários ativos, sua relevância é destacada na economia paulista. Conforme dados de 2016, as MEs e EPPs são titulares de $99 \%$ dos estabelecimentos empresariais, empregam $48 \%$ dos empregados, são responsáveis por $37 \%$ da folha de salários e por $27 \%$ do produto interno bruto estadual (SEBRAE, 2016).

\section{II - Relação de recuperações judiciais em face do total dos empresários}

Para se verificar eventual viés de seleção e precisar ainda mais a utilização do instituto da recuperação judicial pelos MEs e EPPs, procurou-se analisar a frequência relativa dos devedores que possuíam a inclusão em seu nome empresarial das expressões "microempresa", "empresa de pequeno porte" ou sua abreviatura em relação ao total de empresários enquadrados como tais no Registro Público de Empresas Mercantis.

Ressalta-se que, a partir de janeiro de 2018, a LC 155/2016 revogou o art. 72 da LC 123/06 e não exigiu mais das MEs e EPPs a obrigação de acrescentar à sua firma ou denominação as expressões "microempresa", "empresa de pequeno porte" ou suas respectivas abreviações. Dessa forma, a partir de janeiro de 2018, basta o registro dos empresários perante o Registro Público de Empresas Mercantis e a indicação de seu enquadramento como MEs e EPPs. A alteração do parâmetro legal, entretanto, não altera a população da pesquisa, pois, ainda que não precisem mais indicar o enquadramento em seu nome empresarial, como a coleta concentrouse nos processos de recuperação judicial distribuídos entre janeiro de 2010 e julho de 2017 no estado de São Paulo, o nome empresarial continua a ser um parâmetro efetivo.

Do total de 851 processos, $99(11,63 \%)$ recuperações judiciais foram requeridas exclusivamente por MEs, 104 (12,22\%) recuperações judiciais foram requeridas exclusivamente por EPPs e 648 pelos demais empresários ou grupos de empresários $(76,15 \%)$.

“[...] $6^{\circ} \mathrm{Na}$ hipótese de a microempresa ou empresa de pequeno porte incorrer em alguma das situações previstas nos incisos do § $4^{\circ}$, será excluída do tratamento jurídico diferenciado previsto nesta Lei Complementar, bem como do regime de que trata o art. 12, com efeitos a partir do mês seguinte ao que incorrida a situação impeditiva. [...]". 
Tabela 2: Distribuição das empresas requerentes de acordo com o porte.

\begin{tabular}{ccc}
\hline Tamanho da empresa & Frequência & $\%$ \\
\hline Microempresa (ME) & 99 & $11,63 \%$ \\
Pequeno porte (EPP) & 104 & $12.22 \%$ \\
Demais empresários e grupos & 648 & $76.15 \%$ \\
\hline
\end{tabular}

Trata-se de um resultado contraintuitivo. A recuperação judicial corresponde a um conjunto de instituições que procuram auxiliar o empresário a superar uma crise econômicofinanceira conjuntural. Podemos assumir, então, que os empresários de menor porte econômico dispõem de menos reservas, menos ativos, acesso mais dificultoso a crédito e, portanto, estariam mais sujeitos a crises conjunturais.

A participação de MEs e EPPs na distribuição de casos de recuperação judicial deveria, partindo-se dessas premissas, ser superior à sua proporção na distribuição total de empresas. No entanto os dados mostram o contrário.

Em relação à presença dos empresários ativos no estado de São Paulo até 31 de julho de 2017, revelouse que os empresários de grande e médio porte apresentam frequência 44 vezes maior na recuperação judicial dos que os MEs e 2,7 vezes maior do que os EPPs.

Gráfico 2: Frequência relativa de pedidos de recuperação judicial em razão da existência dos empresários ativos, por enquadramento.

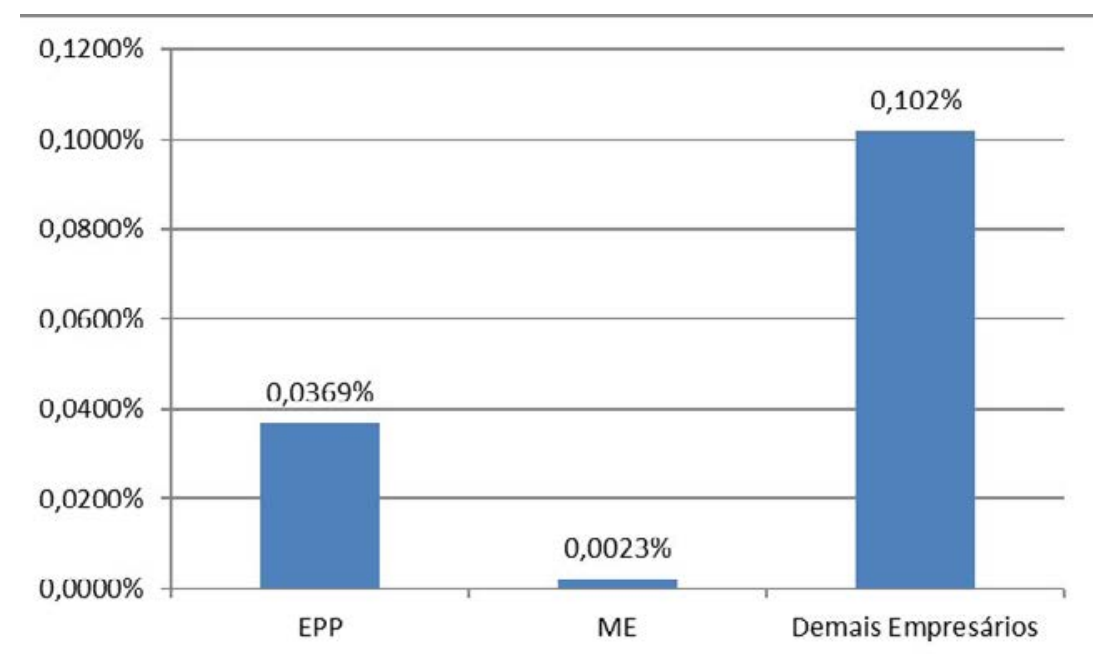

Em linhas gerais, a despeito de representarem $87,97 \%$ das empresas registradas no estado, os MEs e EPPs respondem por apenas $23,85 \%$ das recuperações, o que nos leva a duas possíveis conclusões: A primeira seria que os MEs e EPPs seriam, ao contrário do que imaginávamos, mais resilientes a crises do que os médios e grandes, o que parece contrariar nossa intuição. A segunda possível conclusão é de que a disparidade entre os pedidos de recuperação realizados por MEs e EPPs identifica uma seletividade do procedimento recuperacional.

Para essa hipótese, a pouca adesão ao procedimento pode indicar que a recuperação judicial, enquanto estrutura legal criada pela Lei de Insolvência para obter os objetivos de maximização de valor dos ativos e maior satisfação dos interesses dos diversos envolvidos com o desenvolvimento da atividade empresarial, repele e é infenso à maioria dos $87,9 \%$ dos MEs e EPPs.

Dentre os MEs e EPPs que optaram pelo procedimento, a análise dos principais marcos procedimentais, assim como de eventuais dificuldades, poderá fornecer subsídios para fundamentar por qual razão grande parte dos empresários, mesmo em crise econômico-financeira, não optam pela recuperação judicial como alternativa para superá-la. 


\section{III - O processamento da recuperação judicial}

Do total de 203 MEs e EPPs que ingressaram com recuperação judicial, 106 processos tiveram o processamento da recuperação judicial indeferidos. O deferimento do processamento ocorreu em apenas 97 processos. Mais especificamente, dos 99 casos de ME e 104 de EPP, apenas o percentual de 37,4\% dos processos de ME tiveram o processamento deferido, enquanto houve o processamento de $57,7 \%$ dos pedidos de recuperação judicial de EPP.

Tabela 3: Deferimento e indeferimento do processamento da recuperação judicial.

\begin{tabular}{c|c|c|c|c}
\hline Porte & Pedidos & Deferidos & Indeferidos & $\%$ de deferimento \\
\hline ME & 99 & 37 & 62 & $37,4 \%$ \\
\hline EPP & 104 & 60 & 44 & $57,7 \%$ \\
\hline
\end{tabular}

Em comparação à mediana dos deferimentos dos processos de recuperação judicial do estado de São Paulo, conforme levantamento da $2^{\mathrm{a}}$ fase do Observatório de Insolvência, "a taxa total de deferimento, considerando varas comuns e especializadas, foi de 65,45\%" (WAISBERG et al., 2019, p. 25).

Ao se verificar os fundamentos das decisões judiciais de indeferimento dos processos de recuperação judicial requeridos por MEs e EPPs, constata-se que a maior dificuldade experimentada pelos empresários é a apresentação da documentação exigida. A despeito do permissivo legal de que as MEs e EPPs poderão apresentar livros e escrituração contábil simplificados (art. 51, § $2^{\circ}$, da Lei de Insolvência), verifica-se, pela principal causa de indeferimento, em 78 dos 96 processos com processamento indeferido definido, que o empresário não consegue manter a regularidade de sua escrituração contábil, ainda que simplificada.

Além de não suportar as despesas para a regularização de sua demonstração contábil dos últimos três anos, os custos diretos do processo também são fator impeditivo para o processamento da recuperação judicial. Em 17 processos, o processamento foi indeferido pelo não recolhimento das custas iniciais ou despesas exigidas para a realização da "perícia prévia" determinada pelo juízo.

Tabela 4: Motivos para o indeferimento do processamento da recuperação.

\begin{tabular}{l|c}
\hline Motivos do indeferimento & 71 \\
\hline Falta de documentação contábil indispensável & 8 \\
\hline Custas iniciais & 7 \\
\hline Falta de documento contábil e custas iniciais & 2 \\
\hline Recolhimento de valores para "perícia prévia" & 2 \\
\hline Falta de dois anos & 5 \\
\hline Falta de atividade ou inviabilidade & 1 \\
\hline Falência anterior & 10 \\
\hline Sem definição & 106 \\
\hline Total de indeferimentos & \\
\hline
\end{tabular}

\section{IV - A adoção do procedimento especial}

Essa onerosidade do processo de recuperação judicial aos MEs e EPPs já era conhecida pelo legislador pátrio. Conforme exposto no relatório do senador Ramez Tebet, a desburocratização da recuperação de MEs e EPPs era um dos 12 princípios adotados no PLC 71/2003 e que se converteria na Lei de Insolvência. Para o senador Tebet (2007, p. 395), "a recuperação das micro e pequenas empresas não pode ser inviabilizada pela excessiva onerosidade do procedimento. Portanto, a lei deve prever, em paralelo às regras gerais, mecanismos mais simples e menos onerosos para ampliar o acesso dessas empresas à recuperação".

Para tornar o procedimento menos oneroso, o art. 70 da Lei de Insolvência confere a faculdade aos MEs e EPPs de se submeterem ao procedimento especial de recuperação judicial, o qual dispensará os 
custos de convocação da Assembleia Geral de Credores, na hipótese de oposição de objeções, mas conterá severas restrições aos meios de recuperação judicial disponíveis. Pelo procedimento especial, conforme art. 71 , o plano de recuperação judicial poderá prever deságio, mas o parcelamento do pagamento fica limitado a até 36 parcelas mensais, iguais e sucessivas, acrescidas de juro pela taxa Selic, com o vencimento da primeira parcela no prazo máximo de 180 dias, contados a partir da distribuição do pedido de recuperação judicial. Deverá, ainda, estabelecer a necessidade de autorização do juiz, após ouvido o administrador judicial e o Comitê de Credores, para o devedor aumentar despesas ou contratar empregados.

Em função dessas restrições, do total dos 100 processos com processamento da recuperação judicial deferidos, apenas em quatro processos houve o deferimento do pedido de recuperação judicial na modalidade especial. ${ }^{8}$ A demonstração da falta de incentivos para a adoção do procedimento especial pode ser verificada pela comparação com os meios de recuperação utilizados pelos MEs e EPPs sob o procedimento ordinário de recuperação judicial.

Destaca-se que os quatro processos em procedimento especial tiveram o processamento deferido numa média de 78 dias e todos obtiveram a concessão da recuperação judicial. A pouca quantidade de casos e a grande variação de tempo, entretanto, não permitem se ter certeza quanto à maior ou menor celeridade do procedimento especial a partir da decisão de processamento até a concessão da recuperação judicial, ainda que tenha sido dispensada a Assembleia Geral de Credores. Segue análise casuística das quatro observações:

- No processo 0021309-88.2011, distribuído em 11/05/2011, a publicação da decisão de deferimento do processamento da recuperação ocorreu em 07/07/2011 e a publicação da decisão de concessão em 06/07/2012.

- No processo 3001516-50.2012, distribuído em 30/11/2012, a publicação da decisão de processamento do deferimento da recuperação ocorreu em 27/02/2013 e a publicação da decisão de concessão ocorreu apenas em 16/04/2018.

- No processo 0007268-04.2013, distribuído em 10/07/2013, a publicação do edital de deferimento do processamento da recuperação ocorreu em 19/09/2013 e a publicação da decisão de concessão ocorreu em 06/04/2017.

- Por fim, no processo 1067768-92.2015, distribuído em 08/07/2015, houve a publicação da decisão do deferimento em 13/10/2015 e a publicação da decisão de concessão da recuperação judicial ocorreu em 05/05/2017.

\section{V - Procedimento ordinário de recuperação judicial}

Dos 93 MEs e EPPs que obtiveram o processamento da recuperação judicial pelo procedimento ordinário, 21 deles, equivalentes a 22,58\%, sequer conseguiram chegar à primeira Assembleia Geral de Credores e tiveram a falência decretada. O número é aproximado ao de médios e grandes empresários, cujo percentual foi de $15,7 \%$ para a convolação em falência antes do período de negociação em assembleia.

Se o percentual de convolações em falência antes da deliberação em assembleia não é muito variado, tampouco é diverso o tempo até a obtenção do resultado da deliberação da assembleia.

Tabela 5: Tempo do deferimento até a deliberação final sobre o plano de recuperação judicial.

$\begin{array}{cc}\text { Porte } & \text { Tempo mediano até a concessão } \\ \text { Microempresa (ME) } & 589 \\ \text { Empresa de pequeno porte (EPP) } & 480,5 \\ \text { Médios e grandes empresários } & 544 \\ \text { Grupos societários } & 496\end{array}$

São eles os processos 0007268-04.2013.8.26.0438 e que envolve um microempresário; 0021309-88.2011.8.26.0100, 3001516-50.2012.8.26.0659 e 1067768-92.2015.8.26.0100, todos envolvendo empresários de pequeno porte. 
O resultado das deliberações das Assembleias Gerais de Credores também não varia conforme a recuperanda seja de ME ou de EPP. Dos 72 empresários que conseguiram iniciar as negociações em Assembleia Geral de Credores por ocasião da coleta dos dados, 38 ainda estavam em negociação. Das 34 que conseguiram obter resultado, 31 conseguiram aprovar o plano de recuperação judicial, duas tiveram o plano de recuperação judicial reprovado em Assembleia Geral de Credores e uma faliu durante a negociação.

Tabela 6: Comparação dos desfechos das RJs de EPP e ME vs. demais RJs (desconsiderando as falências decretadas no curso do processo e as que ainda estão em negociação).

\begin{tabular}{l|c|c}
\hline Resultado & \% Médias e grandes & \% EPP e ME \\
\hline Aprovação do plano & $90,1 \%$ & $91,18 \%$ \\
\hline Plano foi reprovado & $9,9 \%$ & $5,88 \%$ \\
\hline Falência durante a negociação & $0 \%$ & $2,94 \%$ \\
\hline
\end{tabular}

\section{VI - Características do plano de recuperação judicial}

Ao se verificar as características dos planos de recuperação judicial apresentados pelas EPPs e MEs em razão do procedimento ordinário de recuperação judicial, pode-se verificar que a previsão de pagamento para os credores trabalhistas e titulares de créditos decorrentes de acidente do trabalho é de 0,9 anos, o que é próximo dos planos de recuperação judicial apresentados pelos empresários com maior faturamento.

Os planos atendem às expectativas quanto a esse tratamento. Isso ocorre porque os créditos trabalhistas ou decorrentes de acidente do trabalho vencidos até a data do pedido, conforme art. 54, ficam limitados ao prazo de pagamento de doze meses no procedimento ordinário de recuperação judicial, o que, todavia, não ocorre no procedimento especial de recuperação de EPP e ME.

Gráfico 3: Previsão de pagamento dos créditos trabalhistas pelas EPPs e MEs.
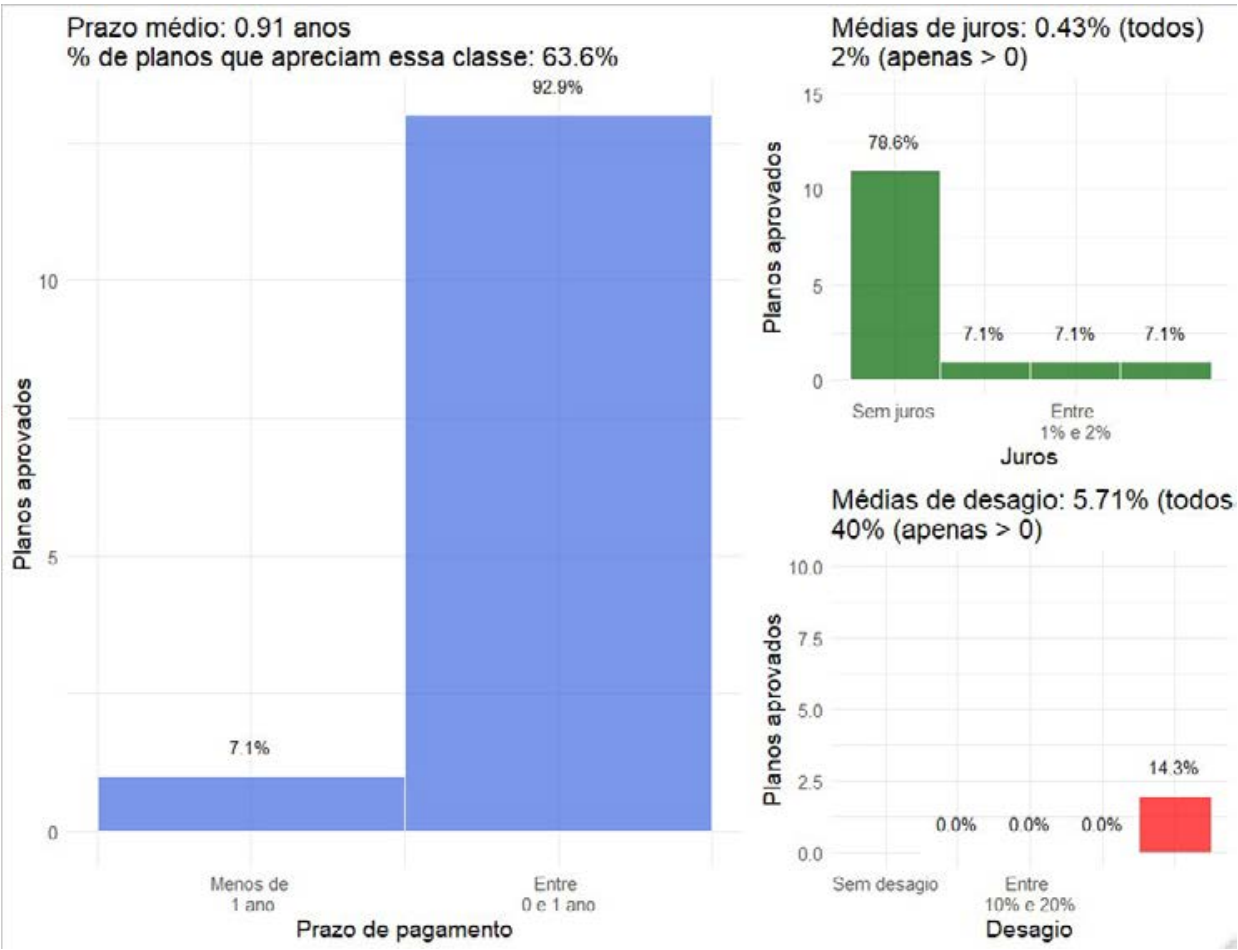
Gráfico 4: Previsão de pagamento dos créditos trabalhistas pelas demais recuperandas.
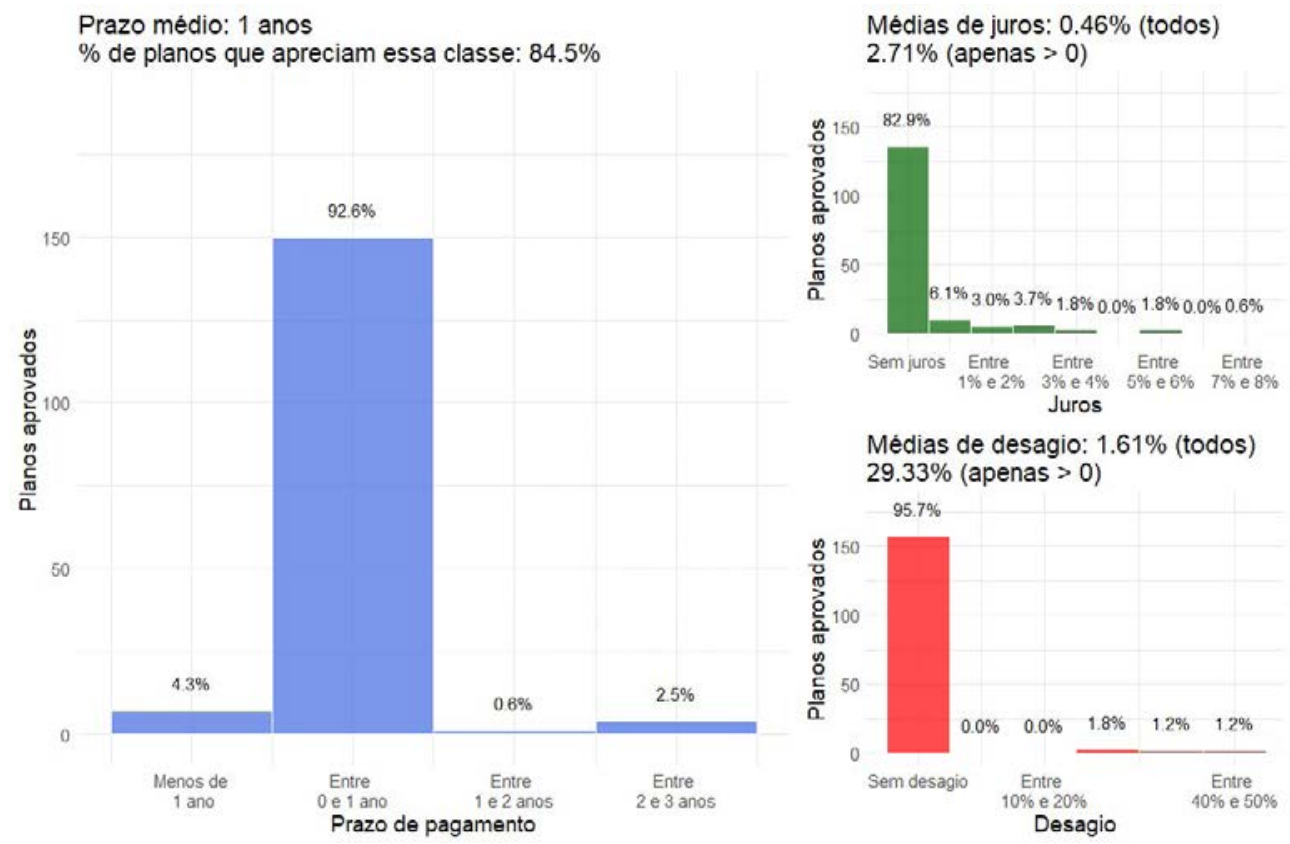

Contudo o procedimento especial de recuperação judicial restringe os pagamentos em até 36 parcelas mensais, iguais e sucessivas, corrigidas monetariamente e acrescidas de juro pela taxa Selic (art. 71). Em comparação à mediana dos planos de recuperação judicial propostos por MEs e EPPs sob o procedimento ordinário, essa restrição não atende à necessidade desses empresários para superarem a crise econômicofinanceira. Os dados revelam que os planos de recuperação judicial preveem prazo médio de 8,31 anos para o pagamento dos credores titulares de créditos com garantia real e de 9,8 anos para o pagamento dos credores quirografários.

Gráfico 5: Plano de recuperação judicial de EPPs e MEs em relação aos titulares de créditos com garantia real.

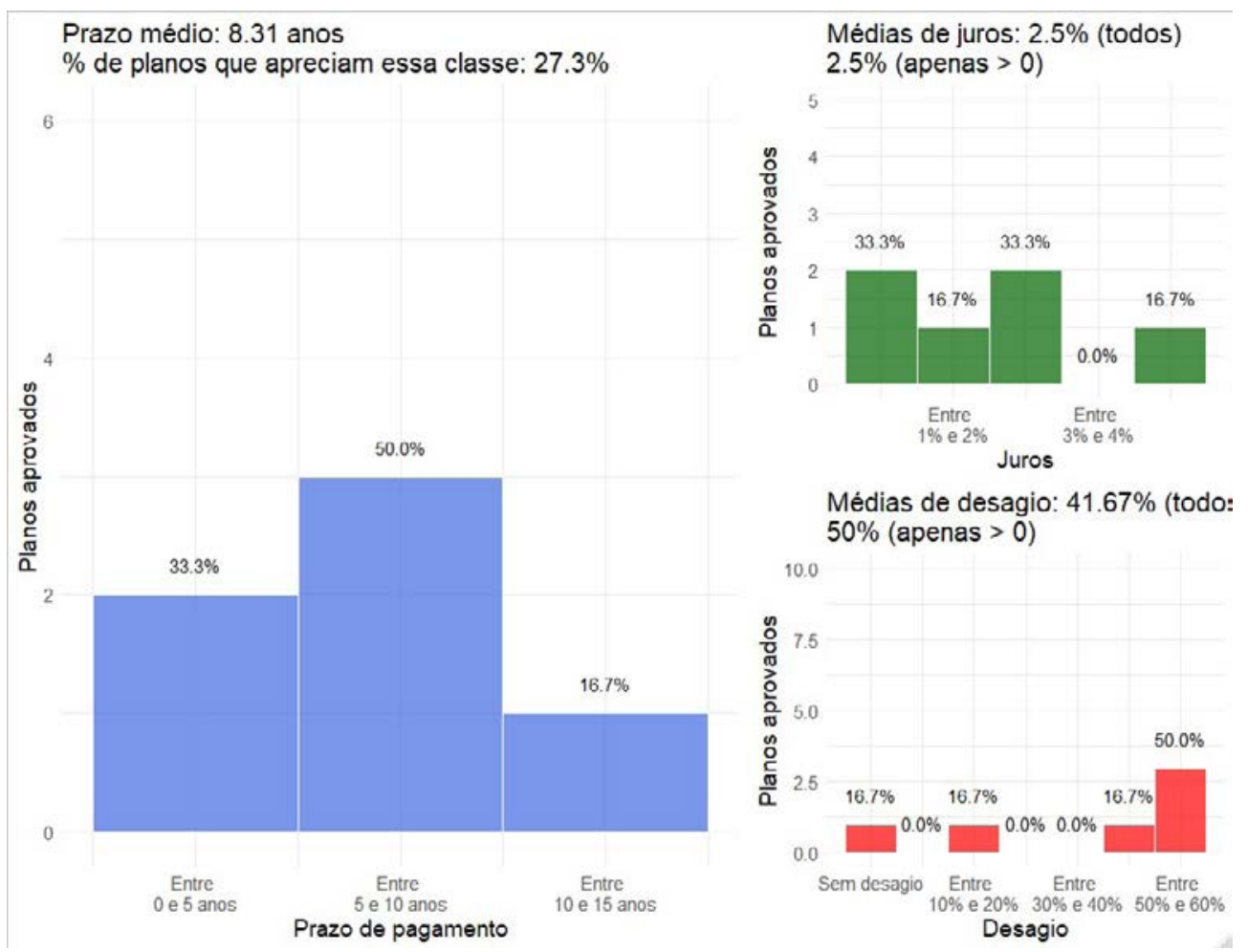


Gráfico 6: Plano de recuperação judicial de EPPs e MEs em relação aos titulares de créditos quirografários.

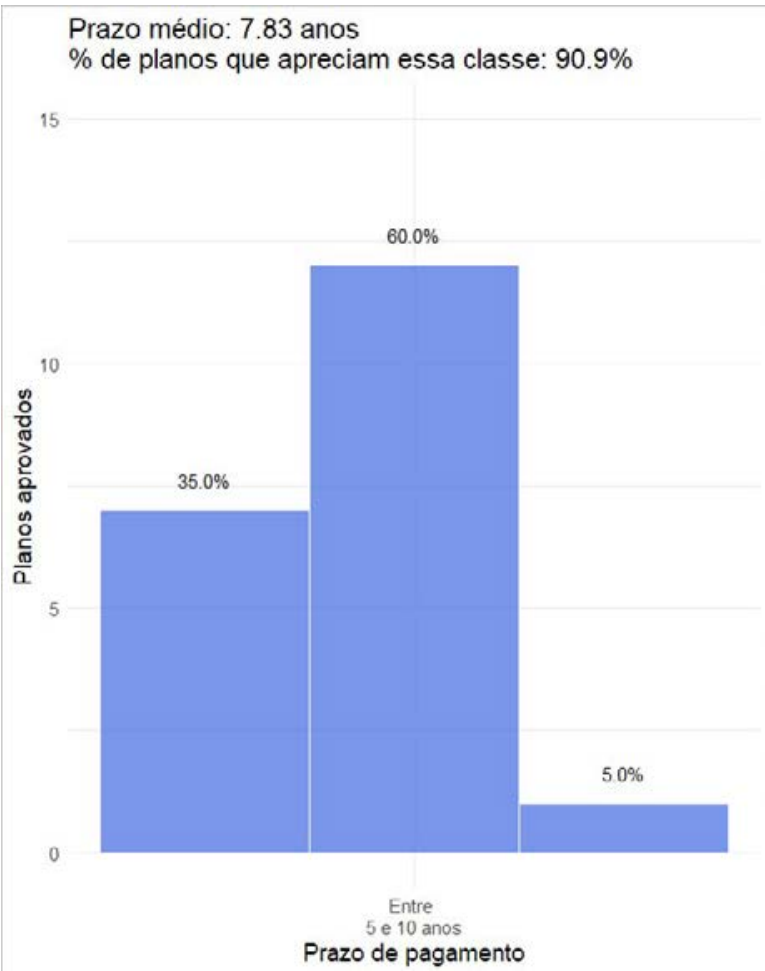

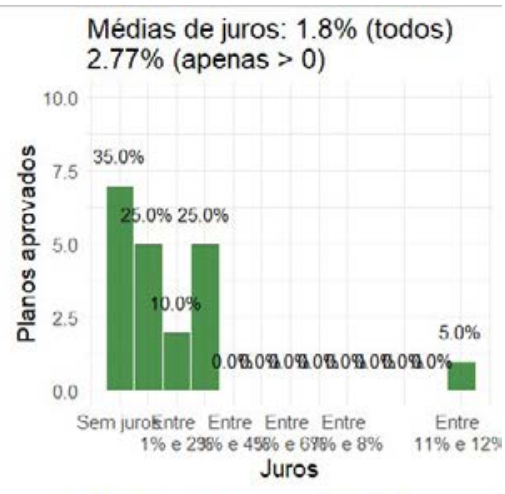

Médias de desagio: $34.25 \%$ (todo $48.93 \%$ (apenas $>0$ )

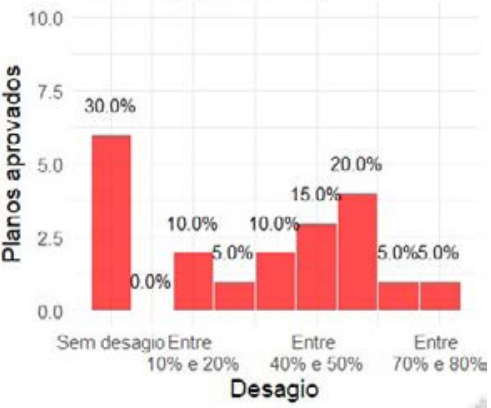

Em relação aos demais empresários, o plano de recuperação judicial médio de MEs e EPPs apresentou prazos ligeiramente mais curtos de pagamento, embora com semelhante previsão de aplicação de correção monetária, juro e deságio explícito (desconto).

Gráfico 7: Plano de recuperação judicial de empresários com maior faturamento em relação aos titulares de créditos com garantia real.
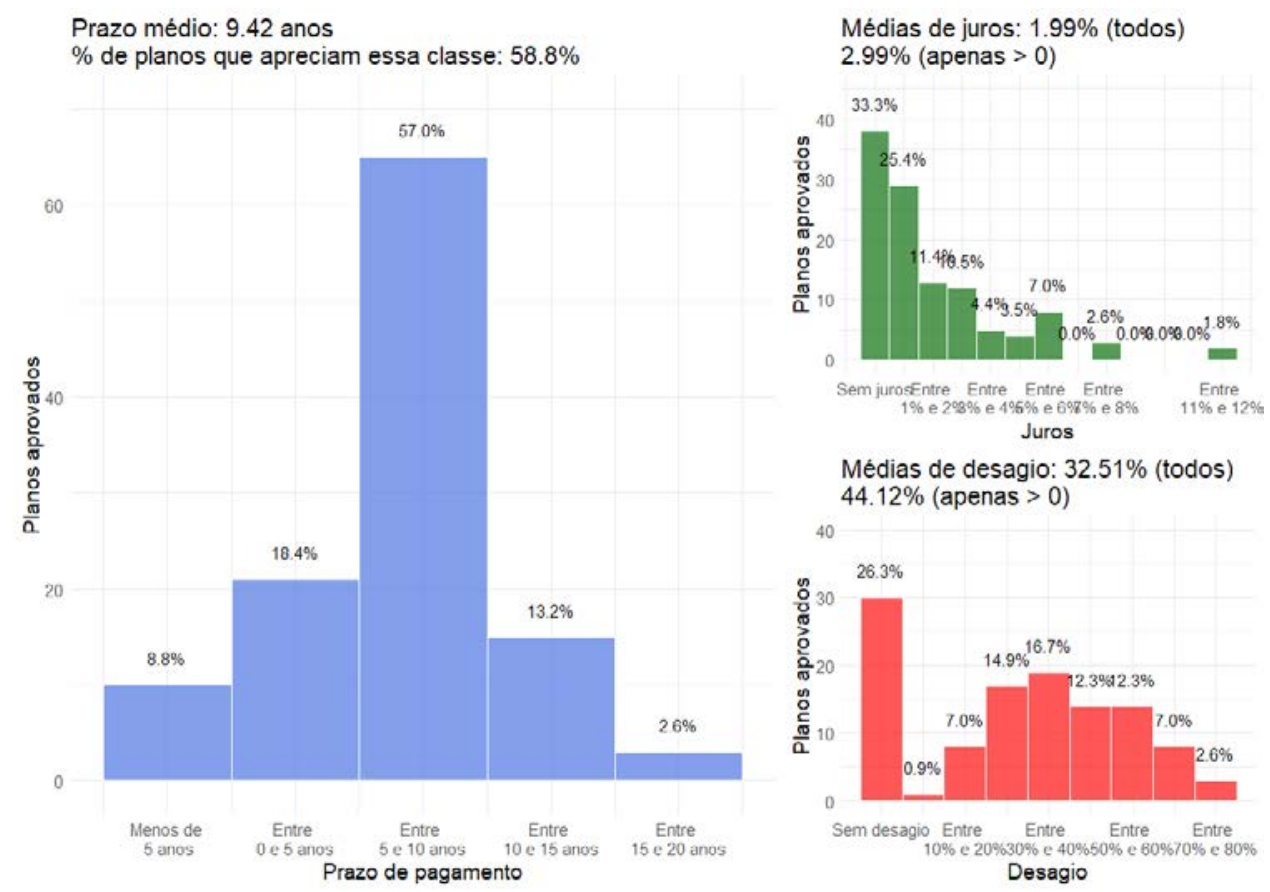
Gráfico 8: Plano de recuperação judicial de empresários com maior faturamento em relação aos titulares de créditos quirografários.
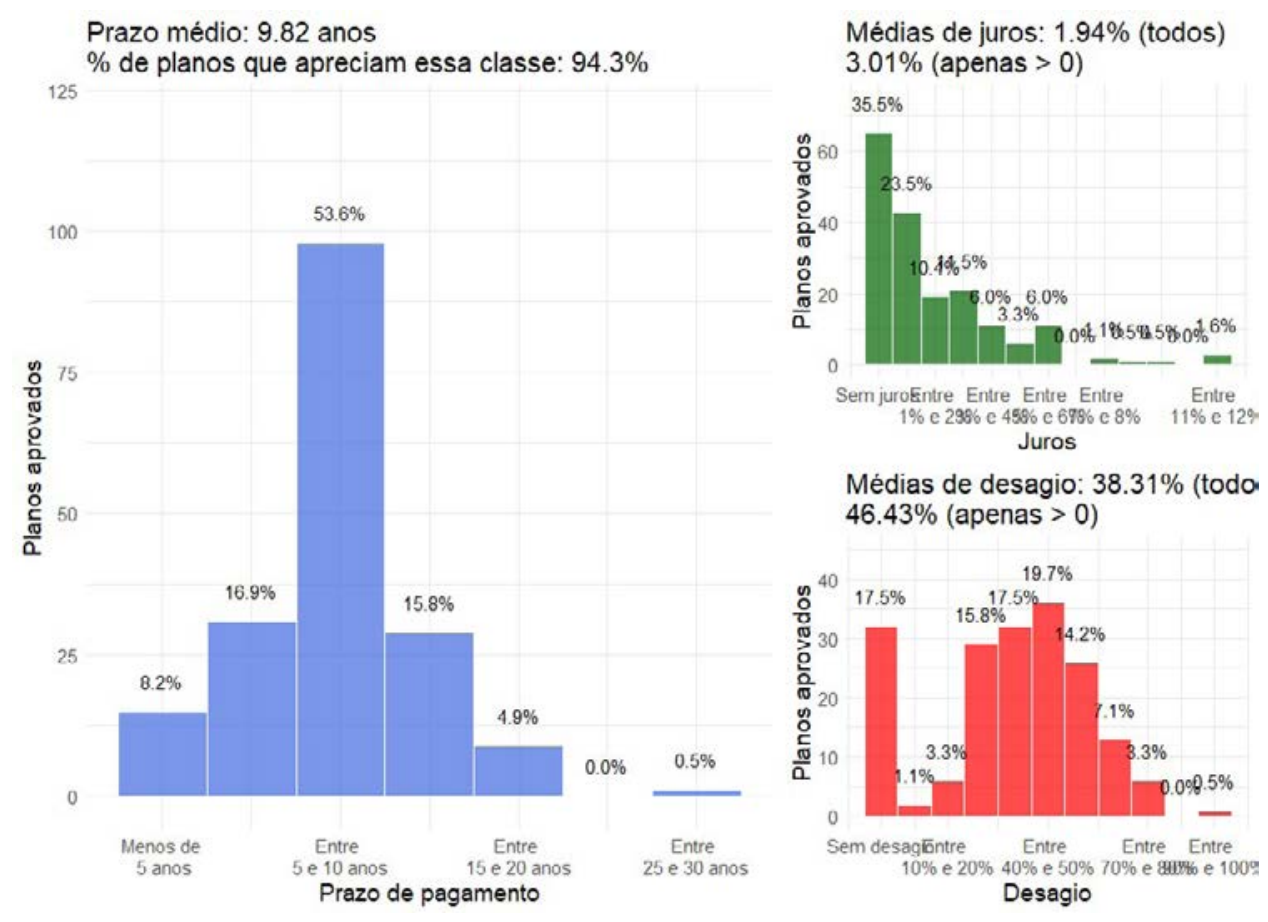

Médias de desagio: $38.31 \%$ (todo $46.43 \%$ (apenas $>0$ )

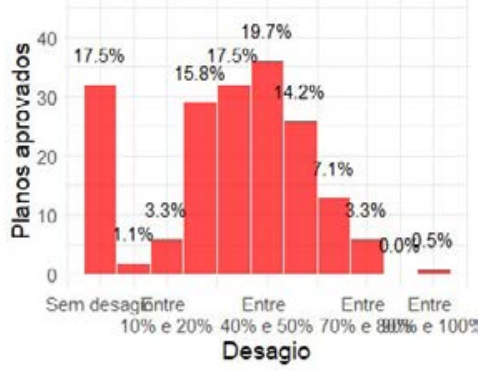

\section{VII - Período de fiscalização judicial}

Das concessões das recuperações judiciais de MEs e EPPs ocorridas pelo procedimento ordinário até junho de 2018, num total de 32 processos, apenas 17 ocorreram até final de junho de 2016, data que permitiria realizar o controle do período de dois anos de fiscalização do plano de recuperação judicial em razão de a coleta de dados para a pesquisa ter se encerrado em junho de 2018.

Desses 17 processos, três tiveram a falência decretada durante o cumprimento do plano de recuperação judicial, enquanto apenas quatro foram efetivamente encerrados sem descumprimento. $O$ restante dos processos, apesar de superado o período de dois anos de fiscalização, não foram encerrados.

Tabela 7: Desfechos das recuperações judiciais concedidas.

\begin{tabular}{c|c|c}
\hline $\begin{array}{c}\text { Desfecho das recuperações judiciais } \\
\text { concedidas }\end{array}$ & $\begin{array}{c}\text { N. }{ }^{\circ} \text { de processos } \\
\text { EPP e ME }\end{array}$ & $\begin{array}{c}\% \text { em relação às EPPs e MEs } \\
\text { concedidas }\end{array}$ \\
\hline Faliram & 3 & $17,65 \%$ \\
\hline Encerraram sem falência & 4 & $23,53 \%$ \\
\hline Ainda em trâmite & 10 & $58,82 \%$ \\
\hline Total de concedidas & 17 & $100 \%$ \\
\hline
\end{tabular}

Diante do custo reputacional e da possível dificuldade de acesso a crédito enquanto perdurar a recuperação judicial, há incentivos para que o empresário devedor que teve a recuperação judicial concedida requeira o encerramento da recuperação judicial imediatamente após o decurso do prazo de dois anos, desde que tenha cumprido todas as obrigações previstas no plano de recuperação judicial e que tenha vencido até dois anos da concessão. Por essa razão, além das duas recuperandas que faliram cumprindo o plano de recuperação judicial, há forte suspeita de que as 10 outras recuperandas, cujo período de fiscalização ainda perdura, têm dificuldade para o cumprimento das obrigações vencidas no referido período.

Por seu turno, o encerramento do processo de recuperação judicial para apenas 03 empresários não permite a conclusão de que a crise que acometia a atividade desses foi superada. Pode-se concluir, apenas, 
que das 17 recuperações judiciais concedidas e cujo período de fiscalização já teria decorrido, somente em três as obrigações previstas no plano de recuperação judicial e vencidas nos dois primeiros anos foram cumpridas.

\section{Conclusão}

Para a ampla maioria dos empresários paulistas, consistentes em MEs e EPPs, bem como para os seus diversos credores, a Lei de Insolvência não se apresenta como alternativa eficiente para a superação da crise econômico-financeira que pode acometer sua atividade.

Ineficiente ao permitir que apenas reduzido percentual desses MEs e EPPs acessem a recuperação judicial e que percentual menor ainda consiga ter deferido o seu processamento de modo a iniciar as negociações coletivas para a superação da crise. A falta de documentação contábil, mesmo que facilitada a sua apresentação pela Lei de Insolvência, e as custas do procedimento revelam-se como barreiras de entrada à negociação coletiva judicial.

A criação do procedimento especial para os MEs e EPPs, por seu turno, não tornou o procedimento judicial mais atraente. O ínfimo percentual de sua adoção pelos empresários no estado de São Paulo demonstra que a pretensa redução legal dos custos e facilitação do procedimento são menos relevantes do que as limitações legais impostas ao plano de recuperação judicial pelo procedimento especial.

Outrossim, ainda que MEs e EPPs consigam deduzir seu pedido de recuperação judicial e obter a concessão da recuperação judicial, apenas pequeno percentual desses empresários consegue superar a crise econômica que acomete sua atividade empresarial a ponto de ter o período de fiscalização judicial encerrado.

Por fim, a disparidade entre, de um lado, as condições de parcelamento, desconto e pagamento dos créditos, obtidas através da aprovação de planos em recuperações judiciais ordinárias, e, de outro, as limitações impostas aos planos especiais de EPPs e MEs, explicam a quase inexistente adoção desse procedimento perante o Poder Judiciário do Estado de São Paulo.

Dessa forma, ao não assegurar a maximização do valor dos ativos e a satisfação dos credores para grande parte dos empresários brasileiros, a Lei de Insolvência não permite a redução dos custos de transação entre os diversos agentes econômicos envolvidos ou o estímulo às atividades empresariais, o que se pretende para o almejado desenvolvimento econômico nacional.

\section{Referências}

ARDIC, Oya; PINAR, Nataliya Mylenko; VALENTINA, Saltane. Small and medium enterprises: a cross-country analysis with a new data set. Washington: World Bank Financial and Private Sector Development Consultative Group to Assist the Poor, 2011. Disponível em: http://elibrary. worldbank.org/ doi/pdf/10.1596/1813-9450-5538. Acesso em: 1 mar. 2020.

ARAUJO, Luiz Alberto David. Curso de direito constitucional. 18. ed. São Paulo: Verbatim, 2014.

BAIRD, Douglas G.; JACKSON, Thomas H. Corporate reorganizations and the treatment of diverse ownership interests: a comment on adequate protection of secured creditors in bankruptcy. The University of Chicago Law Review, Chicago, v. 97, n. 51, p. 97-130, 1984. Disponível em: https:// chicagounbound.uchicago.edu/cgi/viewcontent.cgi?article=2041\&context=journal_articles. Acesso em: 1 mar. 2020.

DAVIS, Ronald B. et al. The modular approach to micro, small, and medium enterprise insolvency. SSRN, Oxford, p. 1-122, jul. 2016. Disponível em: https://papers.ssrn.com/sol3/papers.cfm?abstract_id=2904858. Acesso em: 1 mar. 2020.

COELHO, Fábio Ulhôa. Prefácio. In: NEGRÃO, Ricardo. A eficiência do processo judicial na recuperação de empresa. São Paulo: Saraiva, 2010. p. 7-8.

HART, Oliver D. Different Approaches to Bankruptcy. SSRN, Cambrigde, p. 1-21, Sep. 2000. Disponível em: https://papers.ssrn.com/sol3/papers.cfm?abstract_id=241066. Acesso em: 1 mar. 2020. 
JACKSON, Thomas H. The logic and limits of bankruptcy law. Cambridge: Harvard University Press, 1986.

KUSHNIR, Khrystyna; MIRMULSTEIN, Melina Laura; RAMALHO, Rita. Micro, small, and medium enterprises around the world: how many are there, and what affects the count? Washington: World Bank, 2010. Disponível em: https://www.semanticscholar.org/paper/Micro-\%2C-Small-\%2C-and-MediumEnterprises-Around-the-\%3A-Kushnir-Mirmulstein/99ab1c743d6463e53734a8ad9f19c6450a4aae5c\#relat ed-papers. Acesso em: 1 mar. 2020.

KOROBKIN, Donald R. Value and rationality in bankruptcy decionmaking. William \& Mary Law Review, Williamsburg, v. 33, n. 2, p. 333-366, Feb. 1992. Disponível em: http://scholarship.law.wm.edu/wmlr/vol33/ iss2/2. Acesso em: 1 mar. 2020.

POSNER, Richard A. economic analysis of law. 8. ed. New York: Wolters Kluwer, 2011.

PUGLIESI, Adriana Valéria. Direito falimentar e preservação da empresa. São Paulo: Quartier Latin, 2013.

RAMOS, Tony Luiz. Plano especial de recuperação das micro e pequenas empresas. São Paulo: Iglu, 2006.

SATIRO, F. et al. Panorama da recuperação judicial das me e epp: um estudo comparativo. In: WAISBERG, Ivo; RIBEIRO, José Horácio H. R.; SACROMONE, Marcelo Barbosa (org.). Direito comercial, falência e recuperação de empresas: temas. São Paulo: Quartier Latin do Brasil, 2019. v. 1. p. 17-502.

SILVA, José Afonso da. Curso de direito constitucional positivo. 40. ed. São Paulo: Malheiros, 2017.

SPINELLI, Luís Felipe; SCALZILLI, João Pedro; SILVA, Rodrigo Tellechea. O regime especial da Lei n. 11.101/2005 para as microempresas e empresas de pequeno porte. Síntese, [S.I.], 16 nov. 2011. Disponível em: http://www.sintese.com/doutrina_integra.asp?id=1202. Acesso em: 1 mar. 2020.

SADDI, Jairo; PINHEIRO, Armando Castelar. Direito, economia e mercados. Rio de Janeiro: Elsevier, 2005.

SEBRAE. Panorama das MPEs paulistas. São Paulo: SEBRAE-SP, 2016. Disponível em: https://m. sebrae.com.br/Sebrae/Portal\%20Sebrae/UFs/SP/Anexos/book_pesquisa_sobre_mpes_paulistas_ fe_2016.pdf. Acesso em: 1 mar. 2020.

TEBET, Ramez. Relatório sobre o PLC 71/2003 à Comissão de Assuntos Econômicos do Senado. In: MACHADO, Rubens Approbato (coord.). Comentários à nova lei de falências. 2. ed. São Paulo: Quartier Latin, 2007. p. 19968-19989. Disponível em: https://legis.senado.leg.br/sdleg-getter/documento? $\mathrm{dm}=3499258 \& \mathrm{ts}=1593941462951$ \&disposition=inline. Acesso em: 1 mar. 2020.

VITALE JUNIOR, Ivan Lorena. Recuperação judicial da microempresa e da empresa de pequeno porte. 2012. Tese (Doutorado em Direito) - Faculdade de Direito, Pontifícia Universidade Católica de São Paulo, São Paulo, 2012.

WAISBERG, Ivo et al. Judicial restructuring in the courts of São Paulo: second phase of insolvency monitor. SSRN, [S.I.], p. 1-50, 2019. Disponível em: https://papers.ssrn.com/sol3/papers.cfm?abstract_ id=3378503. Acesso em: 1 mar. 2020.

WARREN, Elizabeth. Bankruptcy policymaking in an imperfect world. Michigan Law Review, Michigan, $\mathrm{n}$. 92, p. 336-387, 1993. Disponível em: https://repository.law.umich.edu/mlr/vol92/iss2/4. Acesso em: 1 mar. 2020.

WORLD BANK. Report on the treatment of MSME insolvency (English). Washington: World Bank Group. 2017. Disponível em: http://documents.worldbank.org/curated/en/973331494264489956/Reporton-the-treatment-of-MSME-insolvency. Acesso em: 1 mar. 2020. 